\title{
A Novel Distributed Large-Scale Demand Response Scheme in High Proportion Renewable Energy Sources Integration Power Systems
}

\author{
Shuai Fan ${ }^{1}$, Guangyu He ${ }^{1, *}$, Kunqi Jia ${ }^{1}$ and Zhihua Wang ${ }^{2}$ \\ 1 School of Electronic Information and Electrical Engineering, Shanghai Jiao Tong University, Shanghai 200240, \\ China; fanshuai@sjtu.edu.cn (S.F.) jiakunqi@sjtu.edu.cn (K.J.) \\ 2 Electric Power Dispatching and Control Center of State Grid Shanghai Municipal Electric Power Company, \\ Shanghai 200122, China; wangzh@sh.sgcc.com.cn \\ * Correspondence: gyhe@sjtu.edu.cn; Tel.: +86-138-1145-8800
}

Received: 11 February 2018; Accepted: 12 March 2018; Published: 16 March 2018

\begin{abstract}
Large-scale demand response (DR) is a useful regulatory method used in high proportion renewable energy sources (RES) integration power systems. Current incentive-based DR schemes are unsuitable for large-scale DR due to their centralized formulation. This paper proposes a distributed scheme to support large-scale implementation of DR. To measure DR performance, this paper proposes the customer directrix load (CDL), which is a desired load profile, to replace the customer baseline load (CBL). The uniqueness of CDL makes it more suitable for distributed schemes, while numerous CBLs have to be calculated in a centralized manner to ensure fairness. To allocate DR tasks and rebates, this paper proposes a distributed approach, where the load serving entity (LSE) only needs to publish a total rebate and corresponding CDL. As for each customer, s/he needs to claim an ideal rebate ratio that ranges from 0 to 1 , which indicates the proportion of rebate $\mathrm{s} /$ he wants to get from LSE. The rebate value for each customer also determines his or her DR task. Then, the process of customer claims for the ideal rebate ratio is modeled as a non-cooperative game, and the Nash equilibrium is proved to exist. The Gossip algorithm is improved in this paper to be suitable for socially connected networks, and the entire game process is distributed. Finally, a large-scale DR system is formulated. The simulation results show that the proposed DR can promote the consumption of RES. Additionally, this scheme is suitable for large-scale customer systems, and the distributed game process is effective.
\end{abstract}

Keywords: Renewable energy resources integration; demand response; game theory; gossip algorithm

\section{Introduction}

High proportion renewable energy sources (RES) integration can effectively solve many environmental issues; thus, it will be one of the characteristics in future power systems [1]. However, the rapid development of RES has brought about several problems in matching the supply and demand in power grids [2]. The intermittent and stochastic characteristics of RES require adequate mechanical inertia and reserves in the whole system, while a large number of conventional generators have to be replaced by RES generators; this is a paradox and causes obstacles to RES integration. Demand response (DR) has been proven to be a very useful and crucial regulation technology in high proportion RES integration power systems [3,4]. Due to the high proportion of RES in power systems, the basic characteristic of DR will be its large scale, and how to effectively manage a large number of wide-area demand-side resources is the main challenge $[5,6]$.

Current DR schemes can be categorized into price-based DR and incentive-based DR [7]. 
In price-based DR (PDR) schemes, price fluctuations in the wholesale market are imposed upon retail customers in a mandatory manner through several retail types, such as time-of-use pricing (TOU), critical peak pricing (CPP) and real-time pricing (RTP) [8,9]. These schemes depend on the retail rate; thus, the utility just needs to publish the same signal to large numbers of customers, which is highly efficient in terms of communication and computation. There are a few studies ([10-13]) that introduced several PDR pilots that have successful results in small-scale DR scenarios. However, there are three potential issues with PDR. First, most of the PDR schemes are involuntary for customers to regulate their electric consumption, whereas voluntary approaches are more recommended in many electric markets [14]. Additionally, the major concern of PDR is its instability, including price volatility and electric consumption rebounds $[15,16]$. In practice, it is very hard for a utility to estimate a suitable retail rate to achieve accurate peak load reduction or shifting because of limited customers' preference parameters and the bounded rationality of customers. At the same time, most customers tend to avoid risk in decision-making [17], but retail rates will be highly dynamic in large-scale DR, which means PDR may, in turn, undermine the customer base. In addition, a dynamic retail rate requires customers to have smart energy scheduling systems, such as [18-20]. But it will take a long time for numerous customers to have such systems, especially in some developing countries. As a result, PDR may be more suitable in small-scale DR but not at a large-scale, and indeed PDR accounts for a smaller part of total DR resources than other DR schemes in recent years [21,22].

In Incentive-based DR (IDR) schemes, customers are rewarded if they respond to the DR signal, such as interruptible load control (ILC) [23,24] direct load control (DLC) $[25,26]$ and peak time rebate (PTR) $[27,28]$. To overcome the limitations of a pre-determined fixed incentive rate, a novel incentive-based DR scheme, called coupon incentive-based DR (CIDR), is proposed [29-31]. This paper also focuses on issues related to IDR.

The study of IDR focuses on how to operate DR resources and how to measure DR performance [32]. For the former, recent studies can be divided into the individual level and the aggregated level. On the individual level, home energy management systems need to schedule flexible loads to respond to the DR signals based on optimization models [16,33,34]. On the aggregated level, load serving entities (LSEs) allocate DR resources according to customer models, such as the utility function $[9,35,36]$ and the price elasticity matrix $[37,38]$, in order to maximize LSEs' welfare or social welfare. To measure DR performance, most studies are based on the customer baseline load (CBL), which is a predicted load curve of the customer in the absence of a DR event. The difference between the actual load and the CBL is thought to be a reduction in the number of customers [39].

Large-scale DR also requires solving these two issues; thus, this paper focuses on how to operate DR resources on an aggregated level and how to measure each customer's performance. A greater number of customers and high DR event frequency are the main challenges in large-scale DR. A distributed DR scheme will have an easier and instant access in large-scale DR due to less communication and computation pressure on the DR center. Additionally, the privacy of customers can be protected in the distributed scheme [40]. On the individual level, there are many distributed DR schemes that have been proposed [2,33]. In regard to the aggregated level, pre-determined fixed incentives can be thought of as a distributed approach; however, it cannot reflect real-time supply-demand status and accurately regulate demand-side resources, while CIDR or other similar better approaches are designed to be a centralized framework. More importantly, the CBL-based DR performance measurement method determines the whole DR process to be centralized because the CBL of each customer has to be established by a centralized DR aggregator. The CBL is a critical part of calculating the incentive payment; therefore, it is unfair to establish CBL by customers individually. For example, the Federal Energy Regulatory Commission (FERC) 745 order requires independent system operators (ISOs) or regional transmission operators (RTOs) to establish the CBL for all DR participants [41]. Nevertheless, in large-scale DR, establishing CBL for numerous customers every day will become a very big challenge for ISOs or RTOs. 
In fact, concerns about CBL in DR have been attended to in recent studies. Except for being an obstacle to distributed DR schemes, there still are other problems, as follows:

(1) The bias of CBL cannot be avoided, and it will result in welfare losses to customers or LSEs [41]. In addition, DR event frequency will be much higher in large-scale DR to integrate a higher proportion of RES, which causes obstacles to establishing accurate CBL, as it is calculated by historical load data in the absence of DR events.

(2) The customers will be capable of strategically increasing CBL and make more load reductions in DR to get more incentives. However, such a reduction is illusory and cannot help regulate the grid. This is called a moral hazard problem $[42,43]$.

In general, models that allocate DR resources on aggregated levels aim to maximize LSE's welfare or social welfare from an ISO/RTO's viewpoint [29]. According to [29-31], this paper also considers LSEs, who can participate in electricity market as strategic bidders, as the DR aggregators. Considering that integrating and consuming more RES can bring much welfare to the whole society, this paper considers a single LSE in a certain region and promoting RES consumption as the goal of large-scale DR. In a real-time economic dispatch, due to the intermittent and stochastic characteristics of RES, the reserve capacity of conventional generators may not be enough and DR events will occur. With this background, our work focuses on designing a novel scheme to allocate DR resources and DR rebates to numerous customers. This paper's contributions can be summarized as follows:

(1) This paper proposes a novel DR performance measurement method called customer directrix load (CDL) to replace CBL. Due to the global uniqueness of CDL, it is more suitable for distributed schemes and the moral hazard problem can be avoided.

(2) The process of allocating DR resources in this paper is designed as a distributed method, which is similar to the red envelop allocation in many social networks. The LSE only needs to publish a total DR rebate and corresponding DR regulation goal to the demand side through social networks, and customer claims for an ideal rebate are performed in a distributed manner. This process is modeled as a non-cooperative game, and the Nash equilibrium is proven to exist.

(3) The Gossip algorithm is used to realize distributed iterations in solving the non-cooperative game. To match factors of socially connected network, the Gossip algorithm is also improved in this paper.

The remainder of this paper is organized as follows: Section 2 covers the proposed DR scheme's timeline; Section 3 introduces the proposed CDL-based scheme; Section 4 models the non-cooperative game of DR customers and distributed solving method. The flowchart of the entire DR program is also shown in this section. A case study and analysis are revealed in Section 5. Finally, Section 6 provides our conclusions.

\section{Timeline of the Proposed DR Scheme}

The proposed DR scheme is implemented in hour-ahead scheduling in a power system. The timeline for the hour-ahead scheduling and the proposed DR scheme is shown in Figure 1. In practice, for example, in California ISO (CAISO), the hour-ahead scheduling is provided approximately $75 \mathrm{~min}$ before the actual beginning of an operating hour while the load and RES forecasts are provided $2 \mathrm{~h}$ beforehand [44]. If the fluctuation of the RES results in an obstacle for conventional generators to adjust, the DR can be implemented to help with regulatation. In the process of DR, the LSE needs to broadcast the total rebate and the CDL to customers through social networks, and each customer claim for their ideal rebate ratio after a limited time, e.g., $5 \mathrm{~min}$. LSE just needs to gather every DR customers' claiming rebate ratio after this limited time to evaluate the total ideal rebate ratio of customers. As for customers, the claiming of the ideal rebate ratio corresponds to the regulation task. During this time interval, customers are able to exchange information with others to choose an optimal strategy and ensure their own welfare maximization. This process is modeled as a 
non-cooperative game and the Gossip algorithm is used to model the information exchanging process between customers, which will be described in Section 4. For the financial settlement, this paper assumes that each customer is trustworthy; thus, the settlement procedure will be completed by the LSE based on each customer's claiming rebate, and customers will get the rebate in their social network account.

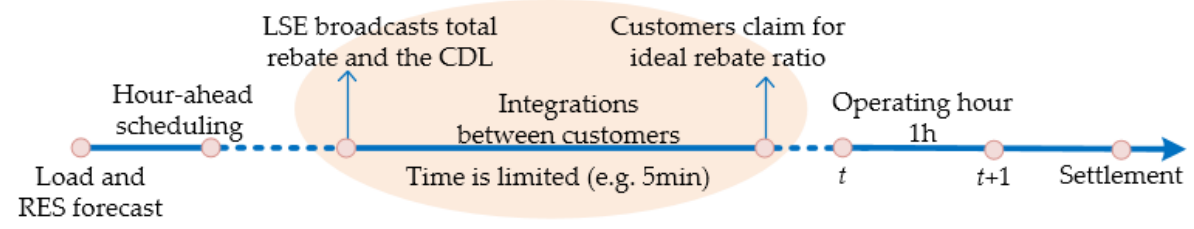

Figure 1. Timeline of the proposed DR scheme.

\section{CDL-Based DR Scheme}

This section introduces the proposed CDL-based DR scheme with respect to two basic issues: how to measure DR performance and how to operate DR resources.

\section{1. $C D L$}

First, CDL is defined. From the LSE's view, there exists a desired total load curve, which supports some of its goals. It is necessary to take into account LSE's own constraints but to consider customers as sufficiently flexible. For example, from the social public view, decreasing coal consumption of conventional generation and consuming as many RESs as possible is the goal. Therefore, the CDL can be defined as a desired load curve that ensures no abandonment of RES. In other words, CDL is a guidance directrix for customers in DR. Additionally, the contribution that each customer makes to promote the total load curve approaching CDL can be quantified to measure its DR performance. According to its definition, CDL is calculated by the LSE, which ensure the uniqueness and fairness of CDL.

This paper studies CDL from the social public viewpoint, that is, the promotion of RES integration. If it comes to other viewpoints, for example, maximizing LSE's welfare, a corresponding CDL can be calculated and it will be studied in the future. In high proportion RES integration power systems, DR resources and conventional generations are controllable resources, while RES and inflexible loads are uncontrollable resources if the abandonment of RES is not considered. The basic goal for controllable resources is to balance uncontrollable resources, which requires that:

$$
P_{c}(t)=-\sum_{i \in \mathcal{I}} D_{i}(t)=P_{d}(t)-P_{r}(t) \quad \forall t \in \mathcal{T}
$$

where $P_{c}(t)$ represents power output of conventional generators at time slot $t ; P_{d}(t)$ represents the inflexible load at time slot $t ; P_{r}(t)$ represents power of RES at time slot $t ; D_{i}(t)$ represents the $i$ th DR customer's load at time slot $t$; and $\mathcal{T}=(1,2, \cdots, T)$ represents the time set and $\mathcal{I}=\{1,2, \cdots, I\}$ represents DR customer set. Let $\Delta(t)=P_{d}(t)-P_{r}(t)-P_{c}(t-1) . \Delta(t)+\sum_{i \in \mathcal{I}} D_{i}(t)$ represents the difference of the demand for conventional generators in two successive time slots. Traditionally, this difference is suitable for load changing only. However, in power systems with RES, there has to be a balance between the superposition of the load and RES, which is known as pure load. In practice, too much regulation of conventional generators is not efficient and is even unfeasible because of constraints of generations, e.g., the ramp rate limit [45]. As a result, LSE requires the difference of the demand for conventional generators in two successive time slots to be limited in a certain range, and if it is likely to exceed the threshold, the DR event will be implemented. According to the definition of 
CDL, DR customers take responsibility for the total exceeded regulation part; thus, the CDL for DR customers is:

$$
P_{C D L}(t)= \begin{cases}\Delta P_{\text {up.max }}-\Delta(t) & D^{*}(t)+\Delta(t)>\Delta P_{\text {up.max }} \\ \Delta P_{\text {down.max }}-\Delta(t) & D^{*}(t)+\Delta(t)<\Delta P_{\text {down.max }}\end{cases}
$$

where $P_{C D L}(t)$ is the calculated CDL at time slot $t ; D^{*}(t)$ is the forecasted flexible load at time slot $t$; and $\Delta P_{\text {up.max }}$ and $\Delta P_{\text {down.max }}$ represent the maximal increasing and decreasing capacity of the total conventional generation, respectively.

In fact, LSE requires DR customers to regulate their load from time slot $t-1$ to $t$ to approach the CDL. The ideal regulation value $P_{\triangle C D L}(t)$ is:

$$
P_{\triangle C D L}(t)=P_{C D L}(t)-\sum_{i \in \mathcal{I}} D_{i}(t-1)
$$

\subsection{Broadcast Total Rebate}

If the DR event needs to be implemented, the LSE will broadcast a total rebate for all the customers who participate in the DR. The rebate value is dynamically determined by LSE. Combining it with the real-time market and calculating an optimal rebate value is suitable for this model from LSE's viewpoint. Because this paper focus on social welfare, the rebate value can be calculated simply as:

$$
\pi_{R}(t)=\sigma \pi_{r}\left|P_{\Delta C D L}(t)\right|
$$

where $\sigma$ is a positive constant and $\pi_{r}$ is the retail rate.

Every customer will receive the total rebate and the CDL, and after a limited time, for example, $5 \mathrm{~min}$, it is required that the customer claims an ideal rebate value ratio $k_{i} \in[0,1]$, which is as much of a proportion of the total rebate the customer wants to obtained. It should be noted that every customer determines their rebate ratio greedily; however, after gathering all the rebate ratios, LSE will calculate the actual ratio $k_{i}^{*}(t)$ for each customer, which ensures that the total rebate ratio $K(t)$ will not exceed the " 1 ":

$$
\begin{aligned}
K(t) & =\sum_{i \in \mathcal{I}} k_{i}(t) \\
k_{i}^{*}(t) & =\left\{\begin{array}{cc}
k_{i}(t) & K(t) \leq 1 \\
\frac{k_{i}(t)}{K(t)} & K(t)>1
\end{array}\right.
\end{aligned}
$$

Thus, the actual rebate for customer $\pi_{i}(t)$ at time slot $t$ is:

$$
\pi_{i}(t)=k_{i}^{*}(t) \pi_{R}(t)
$$

At the same time, getting a rebate also means a corresponding DR task, and the target load for each customer will be:

$$
D_{i}(t)=D_{i}(t-1)+k_{i}^{*} P_{\triangle C D L}(t)
$$

\section{Non-Cooperative Game of Customers}

After receiving the total rebate and the $\mathrm{CDL}$, there is a limited time for each customer to determine an ideal rebate ratio: $k_{i}(t)$. This process is modeled as a non-cooperative game and a decentralized integration method is proposed.

\subsection{Customer Model}

To study the response process, it is necessary to quantify a customer's behavior using a utility function. An acceptable utility function should have a positive marginal return and diminishing marginal rate of return from the economic viewpoint [9]. Different types of utility functions have been 
used in recent studies, for example, a logarithmic function [46], the Diamond growth model [9] and a quadratic function [36]. This paper adopts the quadratic utility function used in [36]:

$$
u_{i}(t)=b_{i}(t) p_{i}(t)-\frac{a_{i}(t)}{2} p_{i}^{2}(t) \quad a_{i}(t), b_{i}(t)>0 \quad p_{i}(t) \in\left[p_{i . \min }(t), p_{i \cdot \max }(t)\right]
$$

where $a_{i}(t)$ and $b_{i}(t)$ are both $\mathrm{t}$ time-varying parameters for each customer; $p_{i}(t)$ represents the power consumption of customer $i$ at time slot $t$; and $p_{i \cdot \max }(t)$ and $p_{i \text { min }}(t)$ represents the maximal and minimal power consumption, which can be evaluated by smart home energy management system [18] according to Physically-Based Load Models (PBLM) [47] and customer's parameters setting. The utility function reflects the customer satisfaction with their electricity consumption; the welfare function $w_{i}(t)$ can be defined as the utility function minus the electricity cost:

$$
w_{i}(t)=u_{i}(t)-\pi_{r} p_{i}(t) \quad p_{i}(t) \in\left[p_{i \cdot \min }(t), p_{i \cdot \max }(t)\right]
$$

The welfare function describes the customer's electricity purchasing behavior quantitatively in each time slot.

If the customer participates in DR, the actual power consumption and cost will be changed because of the received rebate and the change in power consumption. According to (6), (7) and (9), the actual welfare under DR for each customer is:

$$
w_{i}^{D R}(t)=u_{i}(t)-\pi_{r} D_{i}(t)+k_{i}^{*}(t) \pi_{R}(t)
$$

It should be noted that the customer's power consumption is limited by their minimal and maximum power: $D_{i}(t) \in\left[p_{i \cdot \min }(t), p_{i \cdot \max }(t)\right]$. As $D_{i}(t)$ is determined by $k_{i}(t)$ according to (7), when customers decide the ideal rebate ratio, this value is limited not only by 0 to 1 but also indirectly by the power capacity:

$$
\begin{aligned}
& D_{i}(t-1)+k_{i}^{*} P_{\Delta C D L}(t) \in\left[p_{i \cdot \min }(t), p_{i \cdot \max }(t)\right] \& k_{i} \in[0,1] \\
& \Rightarrow \\
& \begin{cases}k_{i} \in[0,1] \cap\left[\frac{p_{i \cdot \min }(t)-D_{i}(t-1)}{P_{\Delta C D L}(t)}, \frac{p_{i \cdot \max }(t)-D_{i}(t-1)}{P_{\Delta C D L}(t)}\right] & K(t)<1 \\
k_{i} \in[0,1] \cap\left[\frac{p_{i \min }(t)-D_{i}(t-1)}{P_{\triangle C D L}(t)} K(t), \frac{p_{i \cdot \max }(t)-D_{i}(t-1)}{P_{\Delta C D L}(t)} K(t)\right] & K(t) \geq 1\end{cases}
\end{aligned}
$$

\subsection{Formulation of Non-Cooperative Game}

Game theory is the study of conflicts and cooperation among rational decision makers [48], and has been used to describe customers' behaviors in DR in recent studies [36]. In the proposed DR scheme, each customer rationally and selfishly chooses a DR strategy to maximize their own welfare, while the total DR rebate is limited. As a result, we can formulate a non-cooperative game and find its solution, that is, the Nash equilibrium. It should be noted that the game process is not controlled by LSE and we formulate this game to study how the customers will respond to our proposed DR scheme. Considering that the theory about non-cooperative game has been introduced in many studies, this paper just uses this theory but does not describe the basic theory again.

The non-cooperative game for customers can be formulated as follows:

- $\quad$ Players: customer $i \in \mathcal{I}$;

- $\quad$ Strategy: the ideal rebate value ratio $k_{i}(t)$ for customer $i$;

- Utility: the welfare function of customer given in (10) and limited to (11).

Then, we need to study whether there exist Nash equilibriums in the proposed scheme. A study (36) gave a lemma about the existence of Nash equilibriums:

If the following conditions are satisfied, there exist Nash equilibriums in the game: 
- The player set is finite.

- The strategy sets are closed, bounded, and convex.

- The utility functions are continuous and quasi-concave in the strategy space.

First, a customer who participates in DR is finite in the proposed DR scheme. Additionally, the strategy for each player is a variable that belongs to a linear constant set according to (11), so the strategy set is closed, bounded and convex. For the welfare function, there is:

$$
\begin{aligned}
& \frac{\partial w_{i}^{D R}(t)}{\partial k_{i}(t)}=\frac{\partial u_{i}(t)}{\partial k_{i}(t)}-\frac{\partial D_{i}(t)}{\partial k_{i}(t)} \pi_{r}+\frac{\partial k_{i}^{*}(t)}{\partial k_{i}(t)} \pi_{R} \\
& =\frac{\partial D_{i}(t)}{\partial k_{i}(t)}\left[b_{i}(t)-a_{i}(t) D_{i}(t)-\pi_{r}\right]+\frac{\partial k_{i}^{*}(t)}{\partial k_{i}(t)} \pi_{R} \\
& =\left\{-a_{i}(t) P_{\Delta C D L}^{2}(t) k_{i}^{*}(t)+\left[b_{i}(t)-a_{i}(t) D_{i}(t-1)-\pi_{r}\right] P_{\Delta C D L}(t)+\pi_{R}\right\} \frac{\partial k_{i}^{*}(t)}{\partial k_{i}(t)}
\end{aligned}
$$

Because customers will estimate $K(t)$ before making a decision, $\frac{\partial k_{i}^{*}(t)}{\partial k_{i}(t)}$ can be thought as a constant when customers choose ideal $k_{i}(t)$. To express it easily, combined with (11), (12) can also be written as an abstract way:

$$
\frac{\partial w_{i}^{D R}(t)}{\partial k_{i}(t)}=M(t) k_{i}(t)+N(t) \quad k_{i}(t) \in\left[\underline{k}_{i}(t), \bar{k}_{i}(t)\right]
$$

where $M(t), N(t), k_{i}(t)$ and $\bar{k}_{i}(t)$ are all constant.

Because

$$
M(t)= \begin{cases}-a_{i}(t) P_{\Delta C D L}^{2}(t) & K(t) \leq 1 \\ -\frac{a_{i}(t) P_{\Delta C D L}^{2}(t)}{K(t)} & K(t)>1\end{cases}
$$

it is easy to know $M(t)<0$, and

$$
\frac{\partial^{2} w_{i}^{D R}(t)}{\partial k_{i}^{2}(t)}=M(t)<0
$$

We can find that the utility in this game is a concave function.

Let $\frac{\partial w_{i}^{D R}(t)}{\partial k_{i}(t)}=0$, we can get the pole point:

$$
\hat{k}(t)=-N(t) / M(t)
$$

The first-order derivative of $w_{i}^{D R}(t)$ maybe have 3 cases, including:

- $\quad$ If $\hat{k}(t)>\bar{k}_{i}(t)$,

$$
\frac{\partial w_{i}^{D R}(t)}{\partial k_{i}(t)}>0
$$

which means that the utility in this game is an increasing function.

- If $\hat{k}(t)<\underline{k}_{i}(t)$,

$$
\frac{\partial w_{i}^{D R}(t)}{\partial k_{i}(t)}<0
$$

which means that the utility in this game is a decreasing function.

- $\quad$ If $\underline{k}_{i}(t) \leq \hat{k}(t) \leq \bar{k}_{i}(t)$

$$
\frac{\partial w_{i}^{D R}(t)}{\partial k_{i}(t)} \begin{cases}>0 & \underline{k}_{i}(t) \leq k_{i}(t)<\hat{k} \\ =0 & k_{i}(t)=\hat{k} \\ <0 & \hat{k}<k_{i}(t)<\bar{k}_{i}(t)\end{cases}
$$

which means that the utility in this game is an increasing function before getting the pole point and then it is a decreasing function. 
In summary, the utility in this game is a concave function, while being monotone increasing or monotone decreasing, or increasing at first and then decreasing. Therefore, this function is quasi-concave in the strategy space. According to the lemma about existing Nash equilibriums, they do exist in this game. It should be noted that if $K(t) \leq 1$ after each customer chooses an ideal strategy, which means the actual rebate ratio equals the ideal rebate ratio, i.e., $k_{i}^{*}(t)=k_{i}(t)$, the whole system reaches the equilibriums. However, if $K(t)>1$, which means the actual rebate ratio does not equal the ideal rebate ratio, i.e., $k_{i}^{*}(t) \neq k_{i}(t)$, customers will recalculate an ideal ratio based on the current $K(t)$. In this situation, customers need to interact with each other and finally reach a balance. The iterative step is as follows:

(1) For customer $i$, initialize $K^{(m=0)}(t)=1$, and calculate an initial ideal rebate ratio $k_{i}^{o p t(m=0)}(t)$ to maximize his/her own welfare, and $m$ represents the iteration number. Because the monotonicity of the welfare function has been analyzed according to (17)-(19), the optimal $k_{i}^{o p t}(t)$ can be determined according to (20):

$$
k_{i}^{o p t}(t)=\arg \max _{k_{i}(t)} w_{i}^{D R}(t)= \begin{cases}\bar{k}_{i}(t) & \hat{k}>\bar{k}_{i}(t) \\ \hat{k} & \underline{\hat{k}}(t) \leq \hat{k} \leq \bar{k}_{i}(t) \\ \underline{k}_{i}(t) & \hat{k}<\underline{k}_{i}(t)\end{cases}
$$

(2) Update the value of $K^{(m)}(t)$ and recalculate an ideal rebate ratio $k_{i}^{o p t(m)}(t)$ according to (20)until it reaches the converge condition:

$$
\left|k_{i}^{o p t(m+1)}(t)-k_{i}^{o p t(m)}(t)\right|<\xi
$$

where $\xi$ is a small positive constant. This iterative process can be characterized by Algorithm 1 . Algorithm 2 is a part of Algorithm 1, which is the process for each customer to evaluate the value of the total rebate ratio of all the DR customers and will be introduced in the next part.

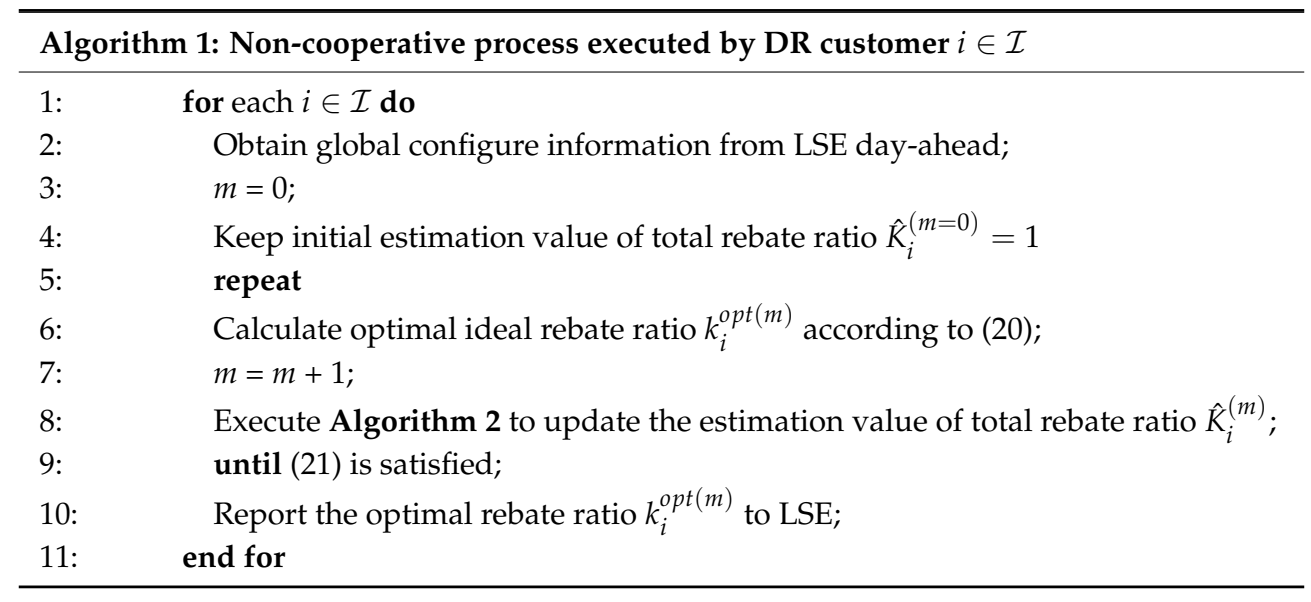

\subsection{Iterative Distributed Scheme Based on Gossip Algorithm}

It should be noted that the customer has to know $K(t)$ when $\mathrm{s} /$ he makes an optimal decision in the previous Section 4.2. There are two ways for customers to get the global information about $K(t)$. The first way is to gather all the optimal decisions from customers and calculate $K(t)$ by a centric node, after which the centric node broadcasts the information about $K(t)$ to all the customers. This approach is efficient only if the communication channels between the centric node and customers are stable and reliable enough, and customers are willing to open their private information before their final decision. More importantly, it is difficult for the centric node to check whether the gathered information is illusive. Another way is to distributedly exchange information with a few customers, but not open it to the public, and then estimate the global information, i.e., estimation value of $K(t)$ based on the 
Gossip algorithm. This approach does not rely on a centric node, which ensures our DR scheme is being totally distributed.

The Gossip algorithm is a non-centric distributed algorithm that has been used in many engineering fields, including power systems. For example, references [49,50] proposed a distributed architecture for managing power flows on distribution grids based on the Gossip algorithm. The basic ideal of the Gossip algorithm is to get global information, such as a sum and average value, based on exchanging one's own information with some neighbor nodes but not gathering the information in a centric node. This algorithm is suitable for the proposed game when customers estimate $K(t)$, because customers are willing to exchange private information with some familiar DR participants based on social networks.

The social network can be represented as a graph $\mathcal{G}(\mathcal{V}, \mathcal{E})$, where $\mathcal{V}$ denotes the set of all nodes in the network and it equals $\mathcal{I}$ as a result, that is, all of the DR program participants. $\mathcal{E}$ denotes the set of logical links between nodes, that is, if the edge is $(i, j) \in \mathcal{E} \quad i, j \in \mathcal{I}$, it means that customers $i$ and $j$ are able to exchange information. The set $\mathcal{N}_{i}$ denotes all the customer nodes who can exchange information with customer $i$, i.e., $\mathcal{N}_{i}=\{j \mid(i, j) \in \mathcal{E}\}$. Define two $I \times I$ matrices, i.e., adjacent matrix $\mathbf{A}$ and degree matrix $\mathbf{D}$, and their entries $a_{i j}$ and $d_{i j}$ are:

$$
\begin{aligned}
& a_{i j}=\left\{\begin{array}{ll}
1 & \text { if }(i, j) \in \mathcal{E}, i \neq j \\
0 & \text { if }(i, j) \notin \mathcal{E}
\end{array} \quad \forall i, j \in \mathcal{I}\right. \\
& d_{i j}=\left\{\begin{array}{ll}
\sum_{j \in \mathcal{I}} a_{i j} & \text { if } i=j \\
0 & \text { if } i \neq j
\end{array} \quad \forall i, j \in \mathcal{I}\right.
\end{aligned}
$$

To estimate $K(t)$, customers can estimate the average of $K(t)$ indirectly, that is, $k_{\text {ave }}(t)=K(t) / I$, and multiply by the total number of DR participants $I$, which will be broadcasted by LSE in advance. In the proposed scheme, the customer who signs in to the DR should be counted as a DR participant, but $\mathrm{s} /$ he can choose $k_{i}=0$ and need not respond to the DR signal. Thus, the total number is a constant for LSE and is easy to get. To distinguish the actual value of $K(t)$ and the customer's estimation value, we use $\hat{K}_{i}(t)$ to represent customer $i$ 's estimation value.

To estimate the average value, the customer needs to update the estimating value using (24) [51]:

$$
k_{\mathrm{ave} . i}^{(r+1)}=\omega_{i i} k_{\mathrm{ave} . i}^{(r)}+\sum_{j \in \mathcal{N}_{i}} \omega_{i j} k_{\mathrm{ave} . j}^{(r)}
$$

where $\omega_{i i}$ and $\omega_{i j}$ are weights. $k_{\text {ave. }}^{(r)}$ represents the average value of $\hat{K}_{i}(t)$ in the $r$ th round for customer $i$. These weights are determined by the Laplacian matrix $\mathbf{L}$, which is defined as:

$$
\mathbf{L}=\mathbf{D}-\mathbf{A}
$$

$\lambda_{i}(\cdot)$ denotes $i$ th largest eigenvalue of a matrix, and defines a constant $\alpha$ :

$$
\alpha=\frac{2}{\lambda_{1}(\mathbf{L})+\lambda_{I-1}(\mathbf{L})}
$$

The weights for customer $i \in \mathcal{I}$ can be expressed as:

$$
\omega_{i i}=1-\alpha d_{i i} \omega_{i j}\left\{\begin{array}{cc}
\alpha & j \in \mathcal{N}_{i} \\
0 & j \notin \mathcal{N}_{i}
\end{array}\right.
$$

Thus, the iterative step is as follow:

(1) Initial $k_{\text {ave. } i}^{(r=0)}=k_{i}^{o p t(m)}$, and calculate weights; 
(2) Exchange information with others and update the estimating average value of $\hat{K}_{i}(t)$ according to (24).

The converge condition is:

$$
\left|k_{\text {ave. } i}^{(r+1)}-k_{\text {ave. } i}^{(r)}\right|<\zeta
$$

where $\zeta$ is a small positive constant.

However, there still exists a problem. Note that the Laplacian matrix $\mathbf{L}$ is hard to obtain not only for customers but also for LSE. In addition, different from [49,50], the network in our scheme is not physically connected but is socially connected, and customers only know the connecting information regarding themselves. That is, there is no one who can gather and calculate an adjacent matrix $\mathbf{A}$ and degree matrix $\mathbf{D}$. To solve this problem, this paper improves the approach to calculating the heights to be adjusted to our DR scheme.

In practice, the number of familiar customers that will exchange information with a certain customer is roughly fixed, or we can regulate a certain constant for each customer in the network to exchange information with, that is, the degree for everyone can be a constant $d^{*}$ in our social network. We randomly create 2000 graphs according to the following rules:

- $\quad$ Each graph has a certain degree $d^{*}$ for every node, and $d^{*}=\{1,2,3, \cdots, 20\}$;

- $\quad$ The total nodes number $I$ range from 100 to 1000 , i.e., $I=\{100,200, \cdots, 1000\}$;

- In a graph with a certain degree and total nodes number, randomly change $\mathcal{E} 10$ times, namely, choose the link ways randomly for 10 times.

Then, we calculate the value of $\alpha$ of each graph. The results are illustrated as Figure 2. It is easy to find that $\alpha$ mainly depends on the degree value $d^{*}$ but not $I$ and $\mathcal{E}$. Thus, we can use the least-square method to fit a curve based on these samples. The fitted curve is calculated as (29) and is shown in Figure 2. It is fitted well with $R^{2}=0.9892$.

$$
\left\{\begin{array}{l}
\alpha\left(d^{*}\right)=h_{3}+h_{1} e^{\left(-h_{2} d^{*}\right)} \\
h_{1}=1.62 \quad h_{2}=0.6018 \quad h_{3}=0.0817
\end{array}\right.
$$

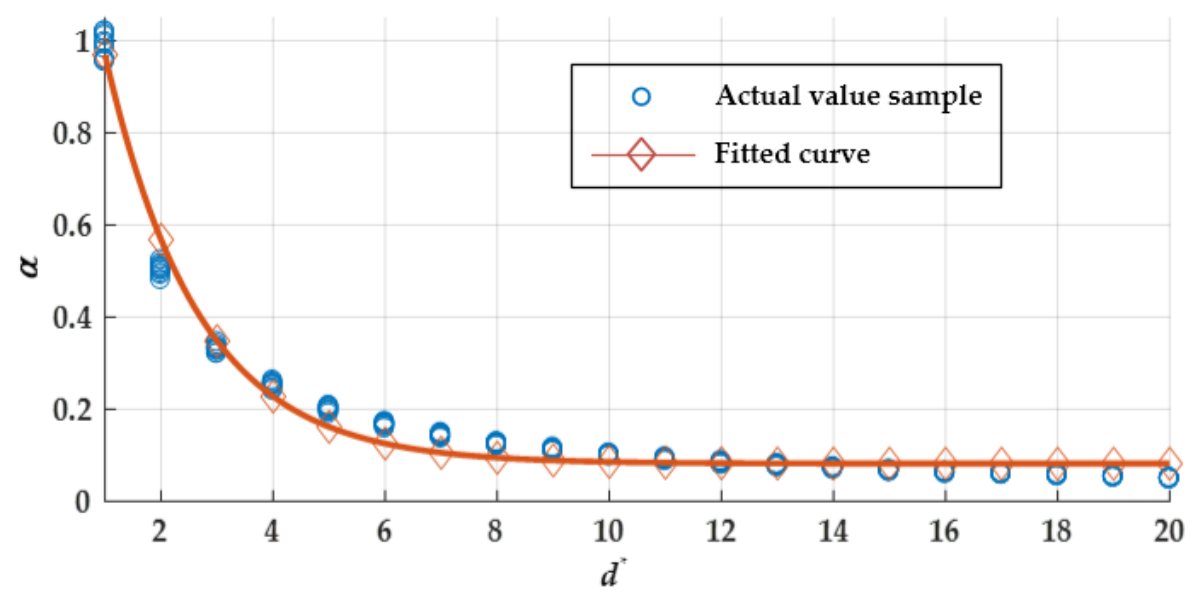

Figure 2. Least square method fitted curve and actual value sample.

As previously described, the degree number of every customer can be regulated as a constant. As a result, $\alpha$ can be estimated easily using (29) based only on the degree number but not detailed global information of adjacent matrix $\mathbf{A}$, which ensures the distributedly integrative process. The process for each customer to estimate $\hat{K}_{i}$ can be characterized by the Algorithm 2 . 


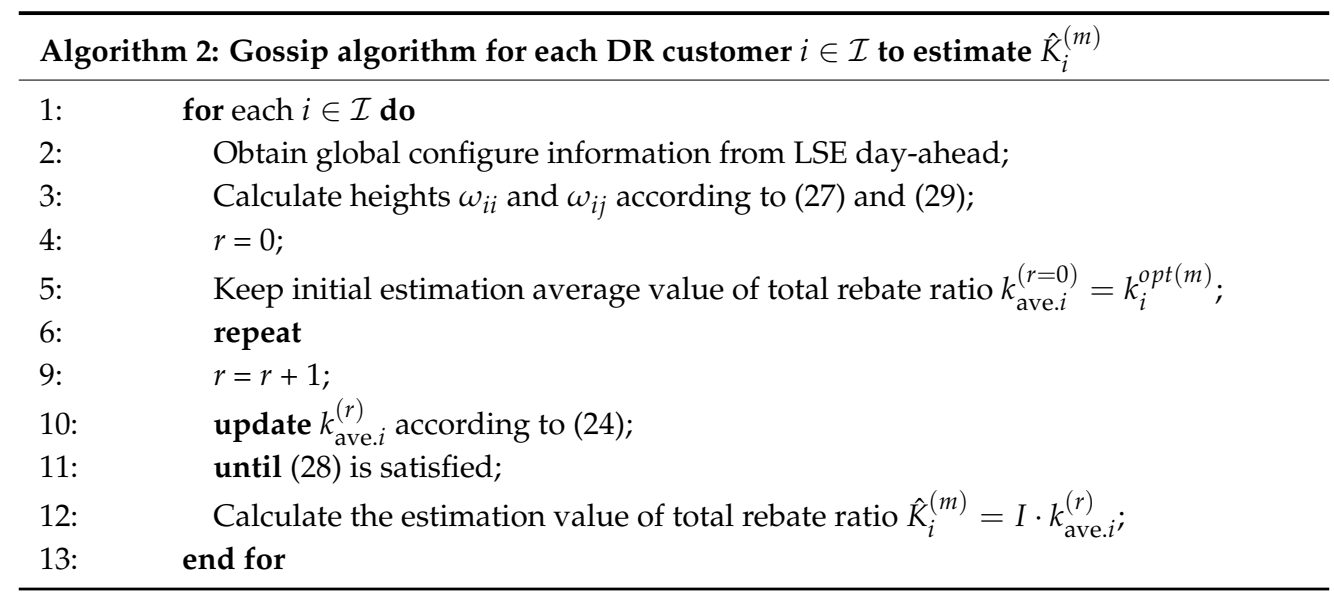

\subsection{Flowchart of the Whole DR Program}

This section concludes the whole processes of the proposed DR scheme and the flowchart is shown as Figure 3.

LSE is the DR aggregator in this paper, who will executes DR program when pure load fluctuation exceeds the maximal or minimal threshold for conventional generations. Section 3 has introduced the task for LSE about broadcasting total rebate and CDL. Then, each DR customer will execute Algorithm 1 , which has been described in Section 4.2, to make an optimal decision of rebate ratio. In order to estimate the total rebate ratio value, Algorithm 2 that has been introduced in Section 4.3 will be executed in the process of Algorithm 1. After receiving all the claiming rebate ratios from customers, DR can be executed and customers will get the rebate.

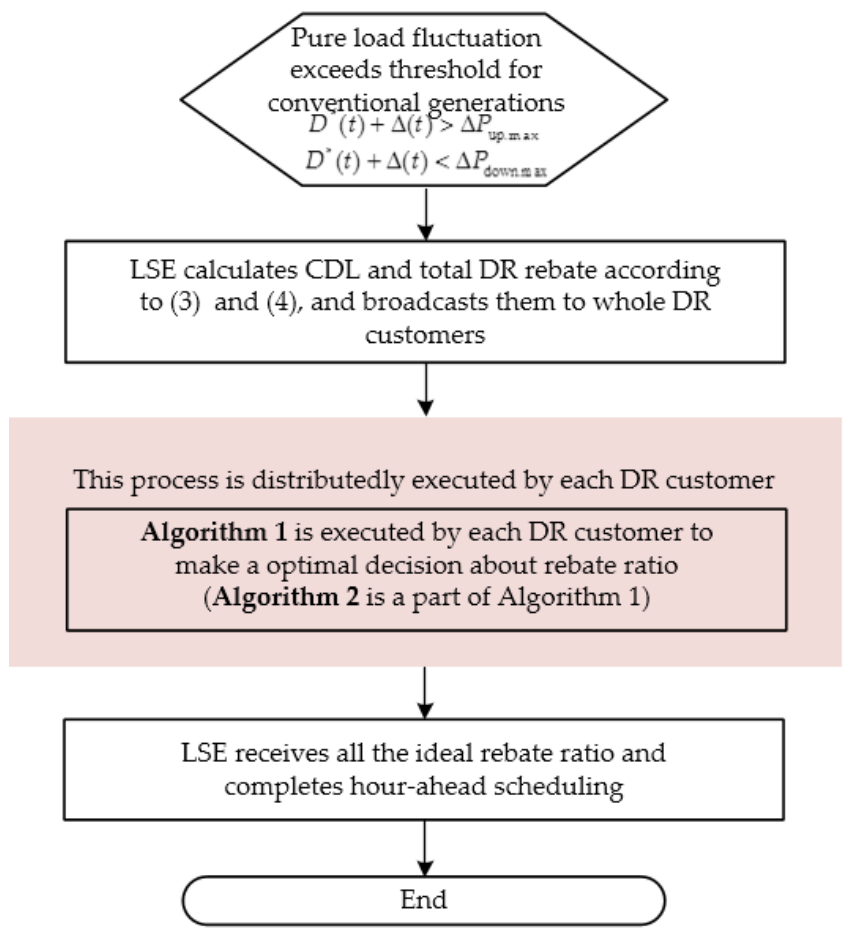

Figure 3. Flowchart of the proposed DR program.

\section{Case Study}

We consider a large-scale DR case to test our proposed DR scheme. To generate a test case, we consider a region with 3000 customers, where $20 \%$ of the customers participate in DR. The load 
curves of each customer without DR are generated by 15 typical load curves [52]. The maximum power of each customer is randomly selected from $[10,20] \mathrm{kW}$ and the minimal power is set as $0 . a_{i}(t)$ of each customer is set as 0.5 in all the time slots, while the retail electricity rate is set as $\$ 0.11 / \mathrm{kWh}$ [29]. We assume these load curves represent customers' optimal power consumption in each time slot, that is, the welfare function can take the maximal value. Thus, we obtain: $b_{i}(t)=\pi_{r}-a_{i}(t) p_{i}(t)$. The RES curve comes from PJM on 2 July 2017 and is expanded 5 times to simulate a high RES proportion integration power system [53]. The conventional generations' maximum and minimum ramp rates are set as: $\Delta P_{\text {up.max }}=3500 \mathrm{~kW} ; \Delta P_{\text {down.min }}=-3500 \mathrm{~kW}$.

\subsection{Simulation Results about Consuming RES}

First, we calculate the pure load of the whole system, which is shown as Figure 4. The pure load represents the normal load minus RES, which will be the actual power output of the conventional generations. However, we can find that the ramp rate is beyond the maximum or minimum rate of conventional generations from time slot 6 to time slot 10 and time slot 14 to 16 due to the sharp decrease and increase of RES. In practice, the ISO has to abandon RES to ensure a balance if there is no DR. This case is shown as Figure 5. Ramp rate constraints of conventional generations can be ensured, while a large amount of RES has to be abandoned to help conventional generations adjust.

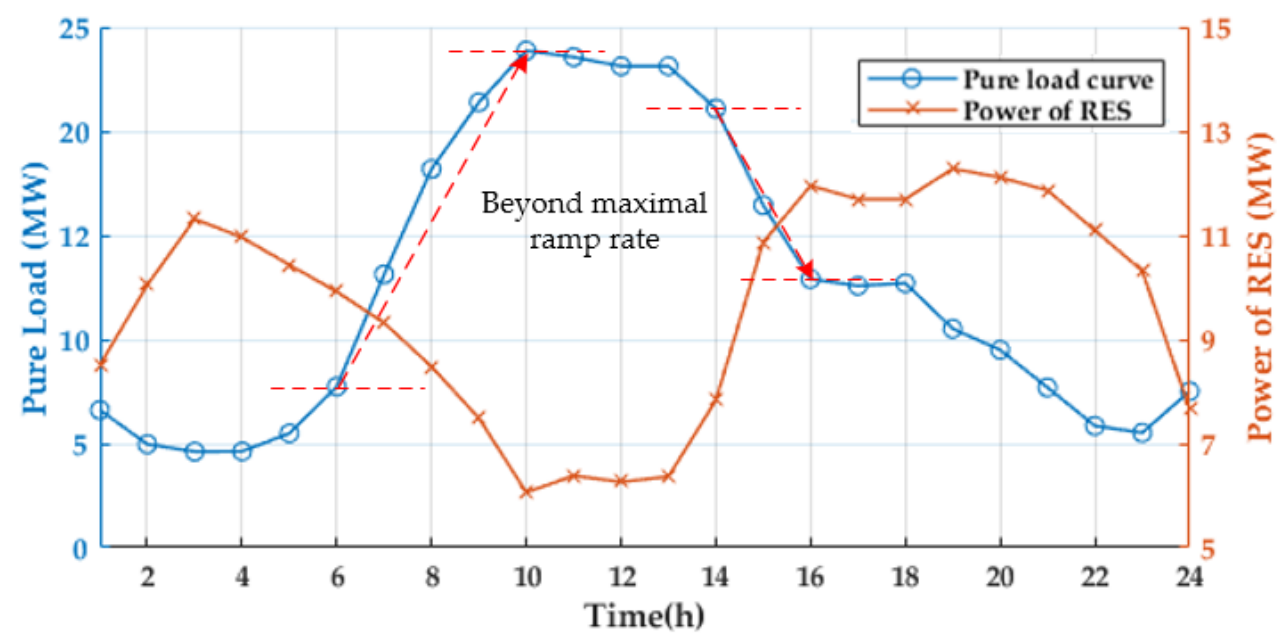

Figure 4. Pure load curve and RES curve.

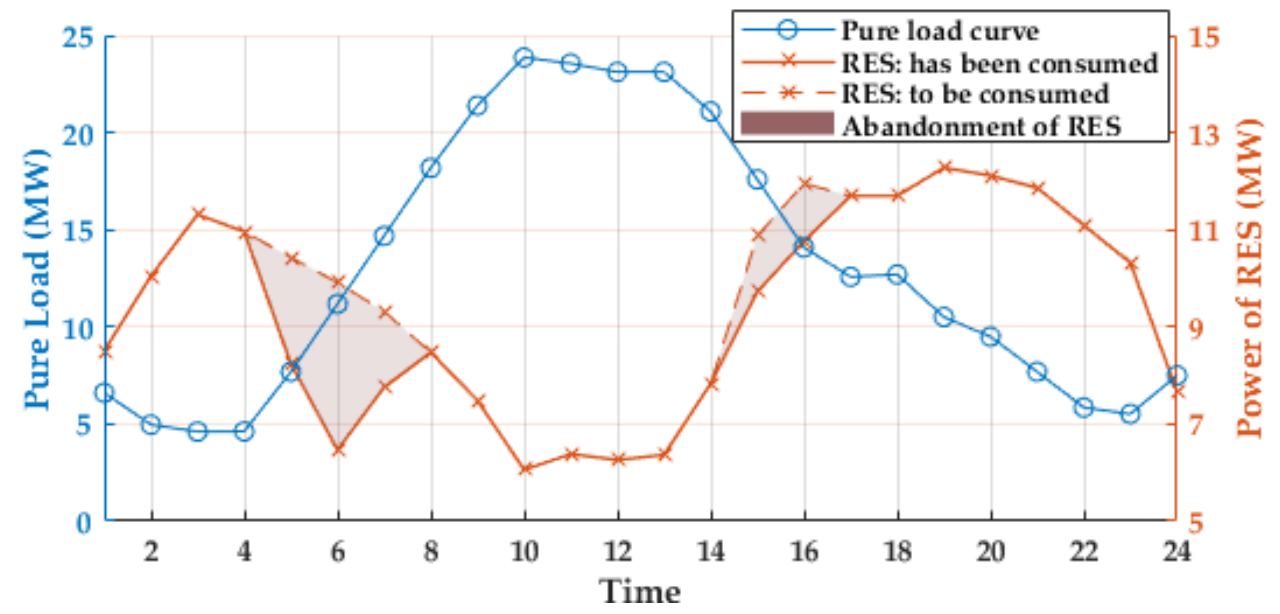

Figure 5. Conventional generation curve and RES curve through abandoning RES to get balance. 
To help consume more RES and get more social welfare, LSE will exceed the proposed DR to help in adjusting. The proposed DR scheme is tested, and its result is shown as Figure 6. Because of the adjusting of DR customers, all the RES can be totally consumed and the ramp rate of conventional generations can also be ensured.

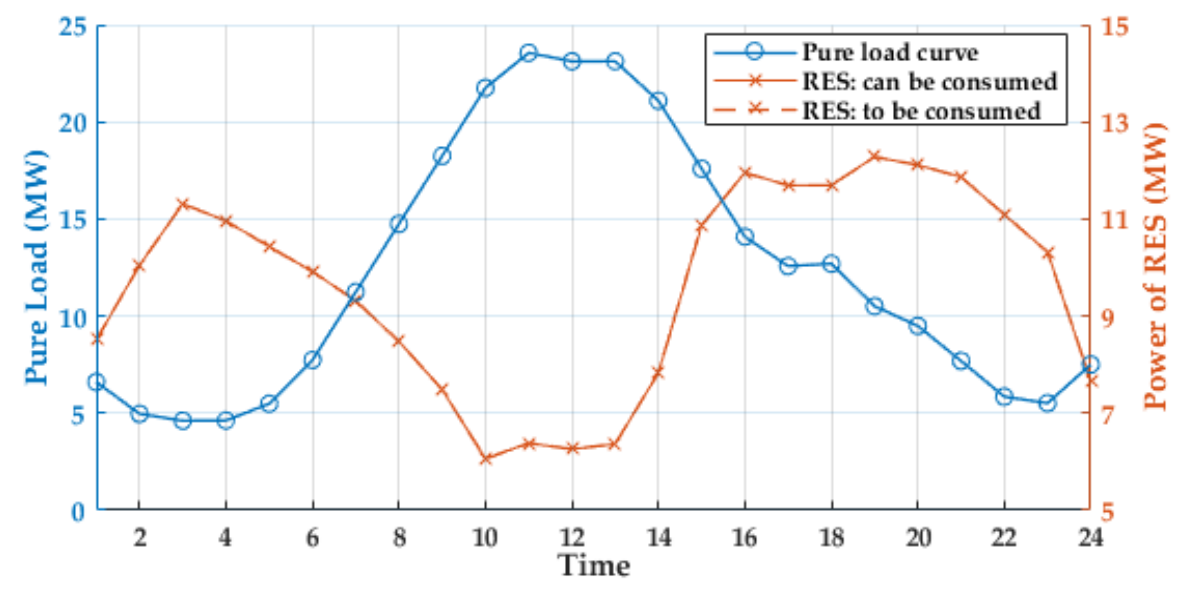

Figure 6. Conventional generation curve and RES curve through the proposed DR scheme to get balance.

In practice, RES usually has an opposite trend with the customer load, which results in violent fluctuation for the pure load. The proposed CDL-based DR scheme is able to promote customers changing their load profile and resulting in the load curves having a closer trend with RES. In order to illustrate this issue, we can define a variable $\rho$ to evaluate two time series' similarity according to [54]. Assume that $X_{1}$ and $X_{2}$ are two time series with the same length, and we transfer each series to 0 to 1 . For example,

$$
X_{1}^{*}=\frac{X_{1}-\min \left(X_{1}\right)}{\max \left(X_{1}\right)-\min \left(X_{1}\right)}
$$

and $X_{2}$ can be transferred to $X_{2}^{*}$, too. Then, $\rho$ is define as the variance of the difference value series of $X_{1}^{*}$ and $X_{2}^{*}$. A larger value of $\rho$ means smaller similarity and larger opposite trend of the two time series. In order to evaluate similarity of a load curve to the RES curve, we let the load curve be $X_{1}$ and RES curve be $X_{2}$. Firstly, the total customer load curve without DR is set to $X_{1}$; we can work out that $\rho=0.387$. If the CDL-based DR scheme is implemented, the value of $\rho$ will decrease to 0.354 . This means the total customer load curve is changed to be closer to the RES curve under the proposed DR scheme. Then, each DR customer's load curve is set to $X_{1}$ one by one and values of $\rho$ are shown in Figure 7. After implement of DR, $\rho$ for each customer changes to become smaller, which means every customers' load curve also becomes closer to the RES curve in the process of DR.

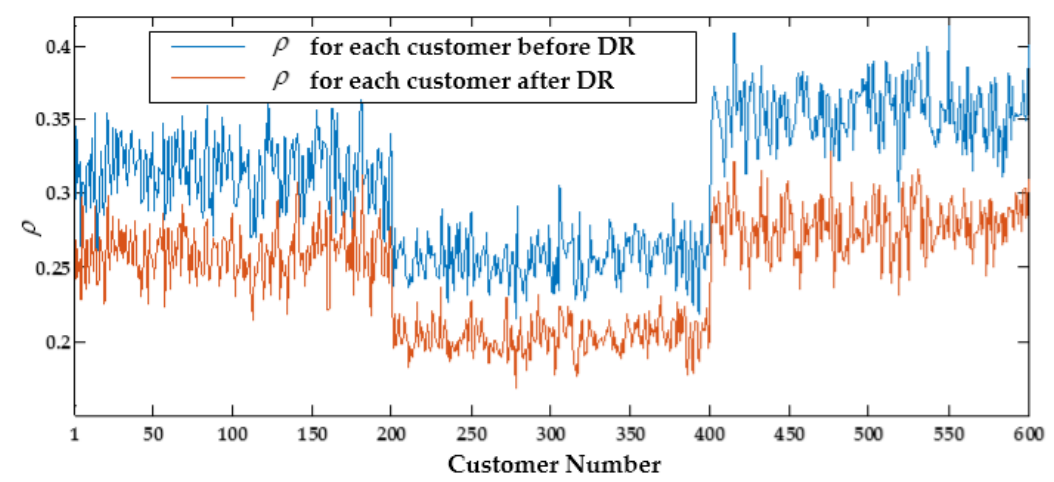

Figure 7. The value of $\rho$ for each customer. 


\subsection{Simulation Results of the Non-Cooperative Game of Customers}

To evaluate the proposed non-cooperative game between customers, Figure 8 illustrates every individual's strategy in a dynamic process at the 7th time slot. It is obvious that every strategy will converge to a value in a few integrations, which is known as the Nash equilibrium. After this static stable strategy is used, no customer has any incentive to unilaterally change this strategy because no one can receive a larger welfare. At the bottom, there is a red line which equals 0 in the entire iteration. The red line means this customer chose not to participate in DR at the 7th time slot because s/he cannot receive a larger welfare, while $s /$ he needs not perform any regulation. It proves our proposed DR scheme is sufficiently voluntary. Figure 9 shows the actual rebate for every customer in DR at the 7th time slot. It is also obvious that every one's rebate can converge into an equilibrium value. It should be noted that the summary of the rebate is a constant and is known as a red envelop published by the ISO. As a result, in the dynamic game process, some customers' rebates will increase while others' will decrease.

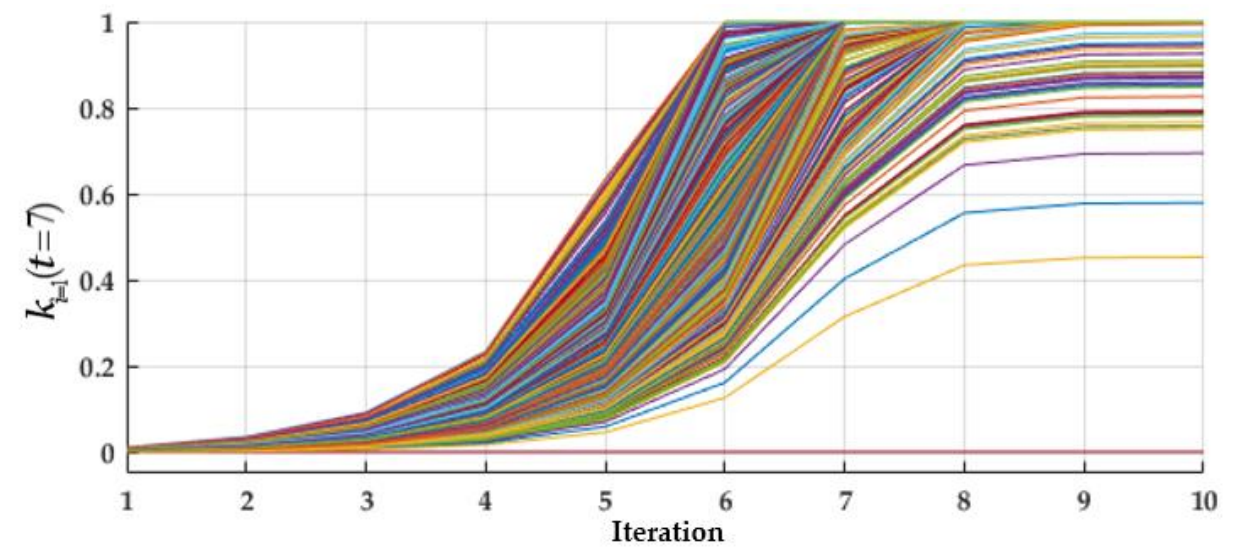

Figure 8. The dynamic process of the non-cooperative process for every customers' ideal rebate ratio.

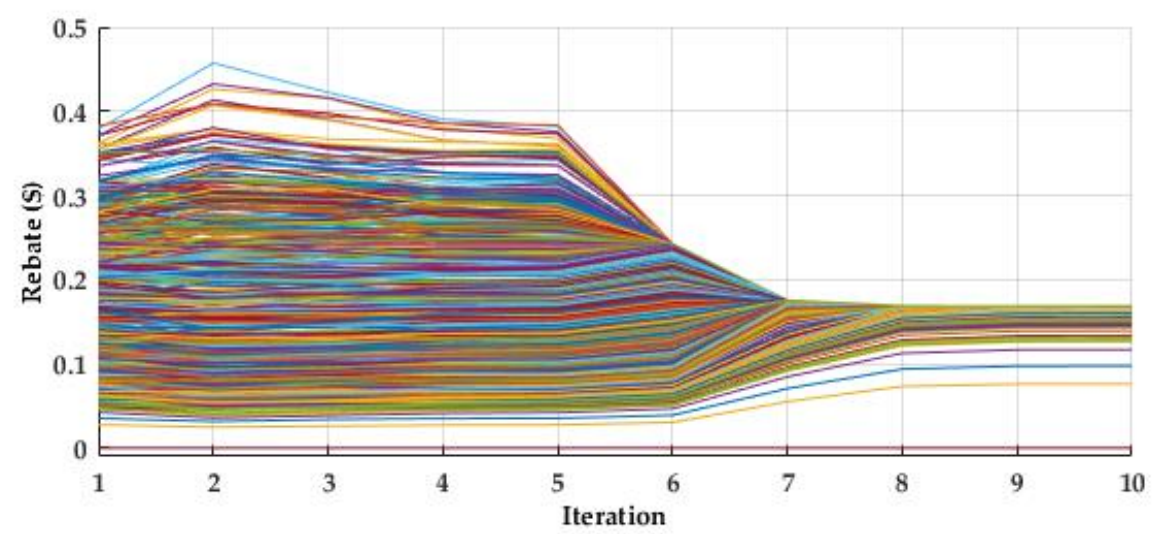

Figure 9. The dynamic process of the non-cooperative process for every customers' actual rebate value.

The scalability of the proposed DR scheme is presented in Table 1. The proposed scheme achieves good scalability with respect to the increasing number of DR customers. It is observed that the iteration number gradually decreases with the increasing number of DR customers. This is because, the total rebate is constant but more customers try to get the rebate, and it means the total rebate ratio will increase quickly. 
Table 1. Iteration in the game process vs. number of DR customers.

\begin{tabular}{cccc}
\hline Number of DR Customers & Iteration & Number of DR Customers & Iteration \\
\hline 150 & 16 & 750 & 8 \\
300 & 15 & 900 & 7 \\
450 & 12 & 1050 & 7 \\
600 & 10 & 1200 & 6 \\
\hline
\end{tabular}

In the dynamic game process, it is very important for every customer to estimate the summary of all other customers' strategy, that is, to estimate $\hat{K}_{i}(t)$. Using our proposed Gossip algorithm, every customer just needs to exchange information with a few familiar customers through the social network and then everyone can get an accurate estimation value. Figure 10 illustrates one of the customer's estimation value at the 7 th time slot with the iterations. It should be noted that in the entire process, Algorithm 1 in the previous flowchart will iterate 10 times, while once $k_{i}^{o p t}(t)$ is updated, the Gossip algorithm, i.e., Algorithm 2, should be executed to estimate the newest $\hat{K}_{i}(t)$. The Gossip algorithm can converge into an accurate value in approximately 9 iterations.

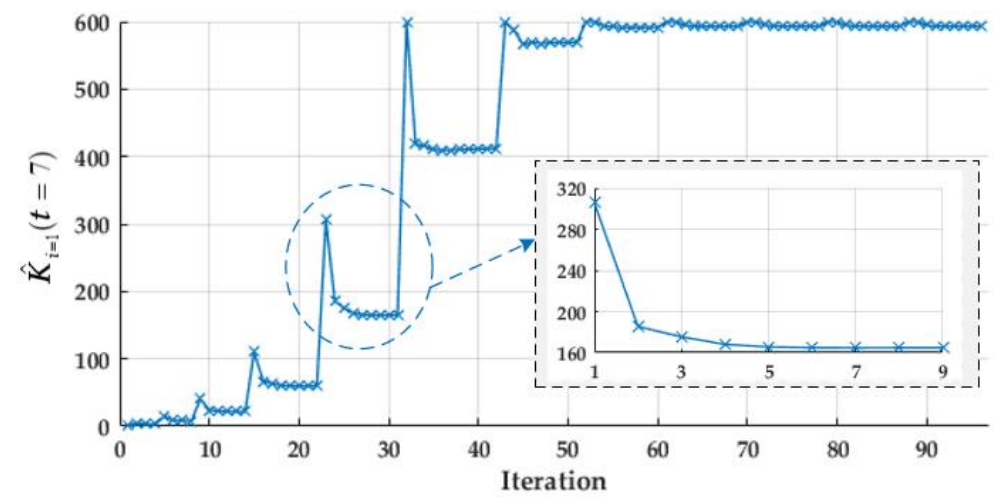

Figure 10. The dynamic process for customer 1 to estimate $\hat{K}_{i=1}(t=7)$ based on the proposed Gossip algorithm.

In Table 2, estimation values and the actual values of total rebate value in every iteration are showed. It can be found that the algorithm is accurate enough to support the customers making decisions in the non-cooperative game

Table 2. Estimation value of Gossip algorithm vs. actual value.

\begin{tabular}{cccccc}
\hline Iteration & Estimation Value & Actual Value & Iteration & Estimation Value & Actual Value \\
\hline 1 & 2.76 & 2.94 & 6 & 411.98 & 412.45 \\
2 & 7.90 & 7.78 & 7 & 569.36 & 569.67 \\
3 & 21.53 & 21.66 & 8 & 591.64 & 591.76 \\
4 & 59.68 & 59.89 & 9 & 593.13 & 593.27 \\
5 & 164.87 & 165.26 & 10 & 593.23 & 593.36 \\
\hline
\end{tabular}

\subsection{Impacts of RES and DR Percentage and Rebate Rate Factor in the DR Scheme}

Additionally, we test the impact of RES percentage, DR percentage and total rebate value on load shedding. We assume RES can be consumed totally, and if there is too large a fluctuation of the pure load, the load shedding of customers has to occur to ensure frequency stability. First, we change the RES percentage at the 7 th time slot from $40 \%$ to $60 \%$. The DR percentage means the ratio of DR participants to all of the 3000 customers, which is changed from $10 \%$ to $60 \%$, while the rebate rate factor $\sigma=0.5$. The simulation result (Figure 11) shows that a larger RES percentage leads to more load shedding because of the rapid random changing and limited generation's ramp rate. On the other 
hand, a higher DR percentage means a larger voluntary and flexible adjusting capacity, which helps decrease load shedding and consumes RES. When the DR percentage is large enough, there will be no load shedding even if there is more RES. Then, the RES percentage is also changed from $40 \%$ to $60 \%$, while the rebate rate factor $\sigma$ changes from 0.2 to 1.8 but DR percentage is set as constant $20 \%$. The simulation result is shown in Figure 12. When the RES percentage is not very high, the higher total rebate can play the same role as the higher DR percentage. However, in regard to a high RES percentage, increasing the total rebate cannot ensure zero (0) load shedding. This phenomenon is shown in the red circle in Figure 12 and means that in the high proportion RES integration power system, increasing DR percentage is very important but increasing rebates may not work well due to the regulation capacity limit of customers.

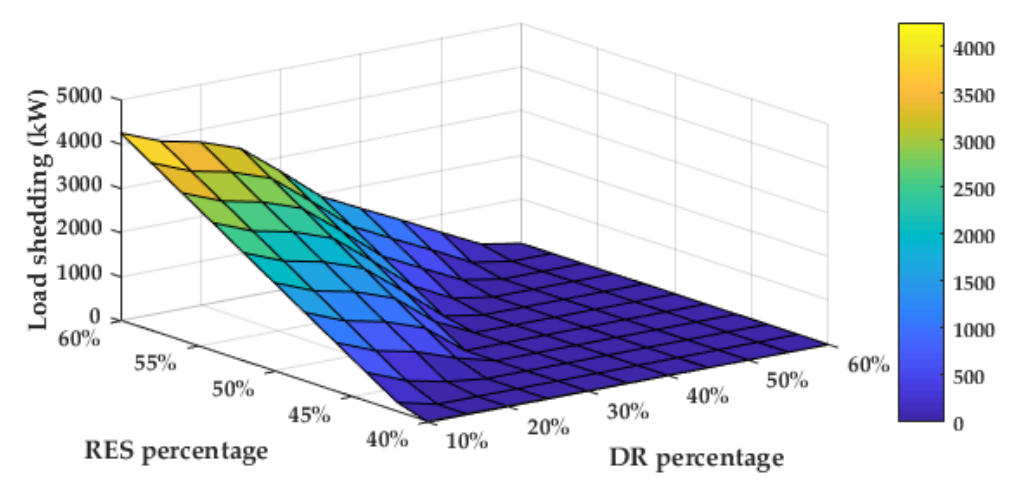

Figure 11. Impact of DR percentage and RES percentage on load shedding.

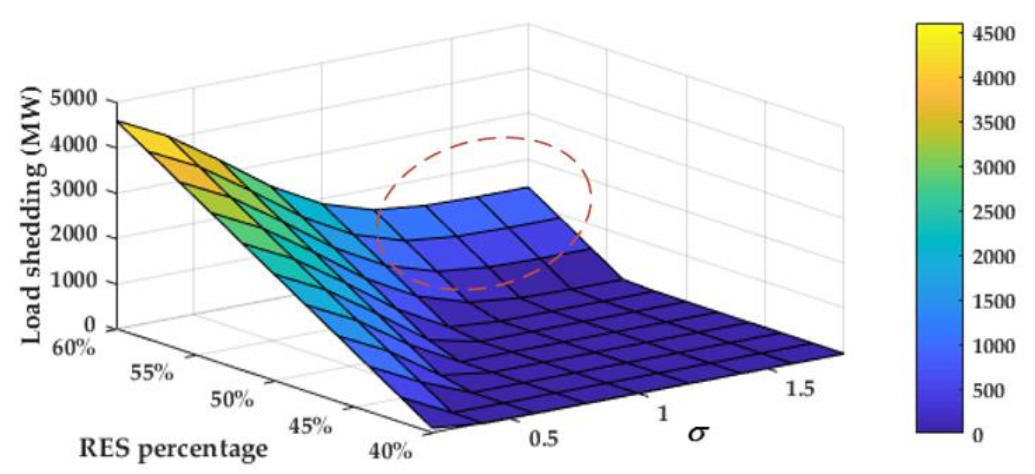

Figure 12. Impact of DR percentage and $\sigma$ on load shedding.

\section{Conclusions}

In this paper, a novel distributed large-scale DR scheme is proposed to promote high proportion RES integration power systems. The idea is to allocate the overall regulation task and DR rebate for numerous customers. To ensure the proposed scheme can be distributed, we replace CBL-based DR performance measurement methods with a CDL-based method, which is known as the desired load profile when the pure load decreases or increases sharply. Additionally, LSE's task in DR is to calculate CDL and publish a total rebate. DR customers choose an ideal rebate ratio to maximize their own welfare and the process is modeled as a non-cooperative game in which the Nash equilibrium is proven to exist. The Gossip algorithm is improved to be suitable for a socially connected network and is used for customers to exchange information with familiar DR participants to estimate global information. A case study proves our proposed scheme is efficient to help consume RES.

This paper simply proposes this novel DR scheme, but further issues need to be studied. First, the physical connectedness of customers, i.e., security-constraints, should be considered to make the result feasible in practice. Second, customers' behavior associated with bounded rationality 
will influence the result of DR, which requires further attention. Moreover, the combination of the blockchain technology with the proposed DR scheme could result in decentralization of the demand side of self-regulation and settlement.

Author Contributions: Shuai Fan, Guangyu He, Kunqi Jia and Zhihua Wang contributed in developing the ideas of this research. Shuai Fan performed this research and write this article. All the authors read and approved the final manuscript.

Conflicts of Interest: The authors declare no conflict of interest.

\section{Nomenclature}

The main notations used throughout the paper are stated below for quick reference. Other symbols are defined as required throughout the text.

$\mathcal{T}$

$\mathcal{I}$

$\mathcal{G}$

$\mathcal{V}$

$\mathcal{E}$

$\mathcal{N}_{i}$

$P_{c}(t)$

$D_{i}(t)$

$P_{C D L}(t)$

$D^{*}(t)$

$\Delta P_{\text {up.max }}$

$\Delta P_{\text {down.max }}$

$k_{i}$

$k_{i}^{o p t}(t)$

$k_{i}^{*}(t)$

$K(t)$

$\hat{K}_{i}(t)$

$\bar{k}_{i}(t), \underline{k}_{i}(t)$

$\pi_{r}$

$\sigma$

$u_{i}(t)$

$\mathrm{w}_{i}(t)$

$\rho$

Set of time, index by $t$

Set of DR customers, index by $i$

Graph of social network

Set of all nodes in the social network

Set of logical links between nodes

Set of all the customer nodes who can exchange information with customer $i$,

Total power output of conventional generators at time slot $t$

Power consumption DR of customer $i$ at time slot $t$;

The calculated CDL at time slot $t$

The forecasted total load of DR customers at time slot $t$

The maximal increasing capacity of total conventional generations

The maximal decreasing capacity of total conventional generations

Claiming rebate ratio of customer $i$ at time slot $t$

Optimal decision value of $k_{i}$

Actual value of rebate ratio for customer $i$ calculated by LSE

Total rebate ratio of all the DR customers

Estimation value of $K(t)$ by customer $i$

Maximal and minimal rebate ratio for customer $i$ at time slot $t$

Retail rate of electricity

Rebate rate factor, a positive constant

Utility of consumer $i$ at time slot $t$

Welfare of consumer $i$ at time slot $t$

A index to evaluate two time series' similarity

\section{References}

1. Ipakchi, A.; Albuyeh, F. Grid of the future. IEEE Power Energy Mag. 2009, 7, 52-62. [CrossRef]

2. Shi, Q.; Li, F.; Hu, Q.; Wang, Z. Dynamic demand control for system frequency regulation: Concept review, algorithm comparison, and future vision. Electr. Power Syst. Res. 2018, 154, 75-87. [CrossRef]

3. Ning, J.; Tang, Y.; Gao, B. A Time-Varying Potential-Based Demand Response Method for Mitigating the Impacts of Wind Power Forecasting Errors. Appl. Sci. 2017, 7, 1132. [CrossRef]

4. Bahrami, S.; Amini, M.H.; Shafie-khah, M.; Catalao, J.P. A Decentralized Electricity Market Scheme Enabling Demand Response Deployment. IEEE Trans. Power Syst. 2017, 1. [CrossRef]

5. Yang, I. Risk Management and Combinatorial Optimization for Large-Scale Demand Response and RES Integration; UC Berkeley: Berkeley, CA, USA, 2015; Available online: https://escholarship.org/uc/item/0zh6b007 (accessed on 20 December 2017).

6. Mhanna, S.; Chapman, A.C.; Verbič, G. A Fast Distributed Algorithm for Large-Scale Demand Response Aggregation. IEEE Trans. Smart Grid 2016, 7, 2094-2107. [CrossRef]

7. Lee, M.; Aslam, O.; Foster, B.; Kathan, D.; Kwok, J.; Medearis, L. Assessment of Demand Response \& Advanced Metering; Federal Energy Regulatory Commission: Norristown, PA, USA, 2010.

8. Chen, Z.; Wu, L.; Fu, Y. Real-Time Price-Based Demand Response Management for Residential Appliances via Stochastic Optimization and Robust Optimization. IEEE Trans. Smart Grid 2012, 3, 1822-1831. [CrossRef] 
9. Mohajeryami, S.; Moghaddam, I.N.; Doostan, M.; Vatani, B.; Schwarz, P. A novel economic model for price-based demand response. Electr. Power Syst. Res. 2016, 135, 1-9. [CrossRef]

10. Boisvert, R.N.; Cappers, P.; Goldman, C.; Neenan, B.; Hopper, N. Customer Response to RTP in Competitive Markets: A Study of Niagara Mohawk's Standard Offer Tariff. Energy J. 2007, 28, 53-74. [CrossRef]

11. Saele, H.; Grande, O.S. Demand Response from Household Customers: Experiences from a Pilot Study in Norway. IEEE Trans. Smart Grid 2011, 2, 102-109. [CrossRef]

12. Vanthournout, K.; Dupont, B.; Foubert, W.; Stuckens, C.; Claessens, S. An automated residential demand response pilot experiment, based on day-ahead dynamic pricing. Appl. Energy 2015, 155, 195-203. [CrossRef]

13. Ameren Illinois, Power Smart Pricing. Available online: https://www.powersmartpricing.org/how-it-works / (accessed on 20 December 2017).

14. PJM, Demand Response. Available online: http://learn.pjm.com/three-priorities/buying-and-selling-energy / markets-faqs/ /media/BD49AF2D60314BECA9FAAB4026E12B1A.ashx (accessed on 20 December 2017).

15. Roozbehani, M.; Dahleh, M.A.; Mitter, S.K. Volatility of Power Grids under Real-Time Pricing. IEEE Trans. Power Syst. 2012, 27, 1926-1940. [CrossRef]

16. Chen, C.; Wang, J.; Kishore, S. A Distributed Direct Load Control Approach for Large-Scale Residential Demand Response. IEEE Trans. Power Syst. 2014, 29, 2219-2228. [CrossRef]

17. Liu, L.; Lyu, X.; Jiang, C.; Xie, D. Decision-Making of Determining the Start Time of Charging/Discharging of Electrical Vehicle Based on Prospect Theory. J. Electr. Eng. Technol. 2014, 9, 803-811. [CrossRef]

18. Amini, M.H.; Frye, J.; Ilić, M.D.; Karabasoglu, O. Smart residential energy scheduling utilizing two stage Mixed Integer Linear Programming. In Proceedings of the North American Power Symposium (NAPS), Charlotte, NC, USA, 4-6 October 2015; pp. 1-6.

19. Amini, M.H.; Nabi, B.; Haghifam, M.R. Load management using multi-agent systems in smart distribution network. In Proceedings of the 2013 IEEE Power and Energy Society General Meeting, Vancouver, BC, Canada, 21-25 July 2013; pp. 1-5.

20. Bahrami, S.; Wong, V.W.S.; Huang, J. An Online Learning Algorithm for Demand Response in Smart Grid. In IEEE Transactions on Smart Grid; IEEE: Piscataway Township, NJ, USA, 2017; p. 1.

21. Goldman, C.; Reid, M.; Levy, R.; Silverstein, A. Coordination of Energy Efficiency and Demand Response; Lawrence Berkeley National Laboratory: Berkeley, CA, USA, 2010.

22. Cappers, P.; Goldman, C.; Kathan, D. Demand response in U.S. electricity markets: Empirical evidence. Energy 2010, 35, 1526-1535. [CrossRef]

23. Chen, C.S.; Leu, J.T. Interruptible load control for Taiwan Power Company. IEEE Trans. Power Syst. 1990, 5 , 460-465. [CrossRef]

24. Huang, K.Y.; Chin, H.C.; Huang, Y.C. A model reference adaptive control strategy for interruptible load management. IEEE Trans. Power Syst. 2004, 19, 683-689. [CrossRef]

25. Hsu, Y.Y.; Su, C.C. Dispatch of direct load control using dynamic programming. IEEE Trans. Power Syst. 1991, 6, 1056-1061.

26. Ruiz, N.; Cobelo, I.; Oyarzabal, J. A Direct Load Control Model for Virtual Power Plant Management. IEEE Trans. Power Syst. 2009, 24, 959-966. [CrossRef]

27. José, V.; Ruiz, F. Demand response: Understanding the rational behavior of consumers in a Peak Time Rebate Program. In Proceedings of the 2015 IEEE 2nd Colombian Conference on Automatic Control (CCAC), Manizales, Colombia, 14-16 October 2015; pp. 1-6.

28. Vuelvas, J.; Ruiz, F. Rational consumer decisions in a peak time rebate program. Electr. Power Syst. Res. 2017, 143, 533-543. [CrossRef]

29. Zhong, H.; Xie, L.; Xia, Q. Coupon Incentive-Based Demand Response: Theory and Case Study. IEEE Trans. Power Syst. 2013, 28, 1266-1276. [CrossRef]

30. Zhong, H.; Xie, L.; Xia, Q. Coupon incentive-based demand response (CIDR) in smart grid. In Proceedings of the 2012 IEEE Power and Energy Society General Meeting, San Diego, CA, USA, 22-26 July 2012; pp. 1-6.

31. Fang, X.; Hu, Q.; Li, F.; Wang, B.; Li, Y. Coupon-Based Demand Response Considering Wind Power Uncertainty: A Strategic Bidding Model for Load Serving Entities. IEEE Trans. Power Syst. 2016, 31, 1025-1037. [CrossRef]

32. Wijaya, T.K.; Vasirani, M.; Aberer, K. When Bias Matters: An Economic Assessment of Demand Response Baselines for Residential Customers. IEEE Trans. Smart Grid 2014, 5, 1755-1763. [CrossRef] 
33. Zheng, L.; Cai, L. A Distributed Demand Response Control Strategy Using Lyapunov Optimization. IEEE Trans. Smart Grid 2014, 5, 2075-2083. [CrossRef]

34. Jovanovic, R.; Bousselham, A.; Bayram, I.S. Residential Demand Response Scheduling with Consideration of Consumer Preferences. Appl. Sci. 2016, 6, 16. [CrossRef]

35. Li, N.; Chen, L.; Low, S.H. Optimal demand response based on utility maximization in power networks. In Proceedings of the 2011 IEEE Power Energy Society General Meeting, Detroit, MI, USA, 24-29 July 2011; pp. 1-8.

36. Chai, B.; Chen, J.; Yang, Z.; Zhang, Y. Demand Response Management with Multiple Utility Companies: A Two-Level Game Approach. IEEE Trans. Smart Grid 2014, 5, 722-731. [CrossRef]

37. Wang, J. A Demand Responsive Bidding Mechanism with Price Elasticity Matrix in Wholesale Electricity Pools; Massachusetts Institute of Technology: Cambridge, MA, USA, 2009.

38. Botterud, A.; Zhou, Z.; Wang, J.; Sumaili, J.; Keko, H.; Mendes, J.; Bessa, R.J.; Miranda, V. Demand Dispatch and Probabilistic Wind Power Forecasting in Unit Commitment and Economic Dispatch: A Case Study of Illinois. IEEE Trans. Sustain. Energy 2012, 4, 250-261. [CrossRef]

39. Farrokh, R.; Ipakchi, A. Demand response as a market resource under the smart grid paradigm. IEEE Trans. Smart Grid 2010, 1, 82-88.

40. Mohammadi, A.; Mehrtash, M.; Kargarian, A. Diagonal Quadratic Approximation for Decentralized Collaborative TSO+DSO Optimal Power Flow. In IEEE Transactions on Smart Grid; IEEE: Piscataway Township, NJ, USA, 2018; p. 1.

41. Mohajeryami, S.; Doostan, M.; Asadinejad, A.; Schwarz, P. Error Analysis of Customer Baseline Load (CBL) Calculation Methods for Residential Customers. IEEE Trans. Ind. Appl. 2017, 53, 5-14. [CrossRef]

42. Mohajeryami, S.; Doostan, M.; Schwarz, P. The impact of Customer Baseline Load (CBL) calculation methods on Peak Time Rebate program offered to residential customers. Electr. Power Syst. Res. 2016, 137, 59-65. [CrossRef]

43. Chao, H.P. Demand response in wholesale electricity markets: The choice of customer baseline. J. Regul. Econ. 2011, 39, 68-88. [CrossRef]

44. Makarov, Y.V.; Loutan, C.; Ma, J.; De Mello, P. Operational Impacts of Wind Generation on California Power Systems. IEEE Trans. Power Syst. 2009, 24, 1039-1050. [CrossRef]

45. Bahrami, S.; Wong, V.W.S. Security-Constrained Unit Commitment for ac-dc Grids with Generation and Load Uncertainty. In IEEE Transactions on Power Systems; IEEE: Piscataway Township, NJ, USA, 2017; p. 1.

46. Fan, Z. A Distributed Demand Response Algorithm and Its Application to PHEV Charging in Smart Grids. IEEE Trans. Smart Grid 2012, 3, 1280-1290. [CrossRef]

47. Zhang, W.; Lian, J.; Chang, C.Y.; Kalsi, K. Aggregated Modeling and Control of Air Conditioning Loads for Demand Response. IEEE Trans. Power Syst. 2013, 28, 4655-4664. [CrossRef]

48. Bauso, D. Game Theory with Engineering Applications; SIAM-Society for Industrial and Applied Mathematics: Philadelphia, PA, USA, 2010.

49. Koukoula, D.I.; Hatziargyriou, N.D. Convergence acceleration of gossip protocols applied for decentralized distribution grid management. In Proceedings of the 2015 IEEE Eindhoven PowerTech, Eindhoven, The Netherlands, 29 June-2 July 2015; pp. 1-6.

50. Koukoula, D.I.; Hatziargyriou, N.D. Gossip Algorithms for Decentralized Congestion Management of Distribution Grids. IEEE Trans. Sustain. Energy 2016, 7, 1071-1080. [CrossRef]

51. Lin, X.; Boyd, S. Fast linear iterations for distributed averaging. Syst. Control Lett. 2004, 53, 65-78.

52. Panapakidis, I.P.; Alexiadis, M.C.; Papagiannis, G.K. Electricity customer characterization based on different representative load curves. In Proceedings of the 2012 9th International Conference on the European Energy Market (EEM), Florence, Italy, 10-12 May 2012; pp. 1-8.

53. PJM, Data Miner 2. Available online: http://dataminer2.pjm.com/feed/gen_by_fuel (accessed on 20 December 2017).

54. Gong, W.; Liu, J.; He, X.; Liu, Y. Load restoration considering load fluctuation rate and load complementary coefficient. Power Syst. Technol. 2014, 38, 2490-2496.

(C) 2018 by the authors. Licensee MDPI, Basel, Switzerland. This article is an open access article distributed under the terms and conditions of the Creative Commons Attribution (CC BY) license (http:/ / creativecommons.org/licenses/by/4.0/). 